\title{
Merotelic attachments and non-homologous end joining are the basis of chromosomal instability
}

\author{
Astrid Alonso Guerrero, Carlos Martínez-A and Karel HM van Wely*
}

\begin{abstract}
Although the large majority of solid tumors show a combination of mitotic spindle defects and chromosomal instability, little is known about the mechanisms that govern the initial steps in tumorigenesis. The recent report of spindle-induced DNA damage provides evidence for a single mechanism responsible for the most prominent genetic defects in chromosomal instability. Spindle-induced DNA damage is brought about by uncorrected merotelic attachments, which cause kinetochore distortion, chromosome breakage at the centromere, and possible activation of DNA damage repair pathways. Although merotelic attachments are common early in mitosis, some escape detection by the kinetochore pathway. As a consequence, a proportion of merotelic attachments gives rise to chromosome breakage in normal cells and in carcinomas. An intrinsic chromosome segregation defect might thus form the basis of tumor initiation. We propose a hypothesis in which merotelic attachments and chromosome breakage establish a feedback loop that results in relaxation of the spindle checkpoint and suppression of anti-proliferative pathways, thereby promoting carcinogenesis.
\end{abstract}

\section{Introduction}

Mitosis comprises a brief period of intense activity in the cell cycle. The segregation of sister chromatids into daughter cells involves moving the largest molecules encountered in nature (the chromosomes) over distances greater than the size of most organelles. To ensure sufficiently rapid chromosome segregation, most eukaryotes connect each centromere to a bundle of parallel microtubules, termed the kinetochore fiber, along which an outward-pulling force moves sister chromatids towards the spindle poles [1]. Chromosome segregation must be completed quickly, since mitosis represses other cell functions [2-4], but accurate distribution of sister chromatids over the two daughter cells is essential for the genetic integrity of the organism. Cells thus impose control on the chromosome segregation machinery through a combination of mechanisms known as the spindle checkpoint. Before chromosomes are segregated, the cell must connect each kinetochore to a single spindle pole through a single kinetochore fiber (amphitelic kinetochore attachment; Fig. 1a). This is the only situation that guarantees the fidelity of chromosome segregation, and the cell will attempt to

*Correspondence: kvanwely@cnb.csic.es

1 Department of Immunology and Oncology, Centro Nacional de Biotecnología/CSIC, Darwin 3, UAM Campus Cantoblanco, 28049 Madrid, Spain Full list of author information is available at the end of the article delay anaphase onset if these requirements are not fulfilled. Satisfaction of the mitotic checkpoint marks a point of no return, and overall chromosome movement continues in anaphase even if spindle attachments are disturbed [5,6]; this means that spindle errors can only be corrected within a limited time window, and that undetected kinetochore attachment errors can alter the genetic makeup of daughter cells.

In addition to correct amphitelic attachment, several errors can occur in microtubule/kinetochore coupling (Fig. 1b, c, d). Individual kinetochores might not attach (monotelic attachment), and are left behind once chromosome segregation is initiated at anaphase. Kinetochores of both sister chromatids might attach to microtubules from a single spindle pole (syntelic attachment), and run the risk of segregation into the wrong daughter cell. A single kinetochore might capture microtubules from both spindle poles (merotelic attachment), which places physical stress on the centromere as the microtubules start to pull. The first two errors result in loss of spindle tension, are sensed as a lack of kinetochore stretch, and trigger a strong signal for mitotic checkpoint activation [7]. Merotelic attachments generate kinetochore tension, however, and do not always activate the spindle checkpoint [8-10]. Although merotelic attachments are potentially harmful, they are relatively com- 
(a) Amphitelic attachment

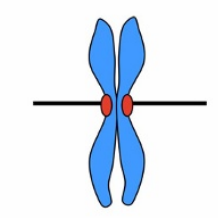

(b) Monotelic attachment

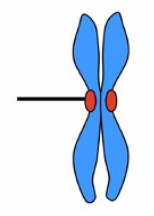

(c) Syntelic attachment

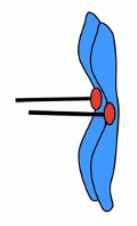

(d) Merotelic attachment
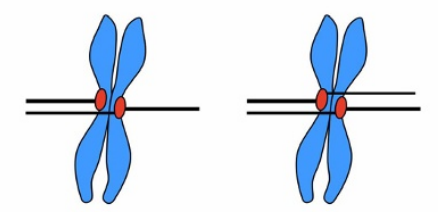

Figure 1 Spindle attachment defects. (a) In amphitelic attachment, the sister kinetochores are correctly connected to microtubules from opposite poles, resulting in a bioriented chromosome. (b) In a monotelic attachment, only one of the sister chromatids is connected to a spindle pole; the chromosome is mono-oriented. (c) In a syntelic attachment, both sister kinetochores are attached to a single spindle pole, and the chromosome is mono-oriented. (d) In a merotelic attachment, usually one or, rarely, both sister kinetochores are connected to both poles instead of one. Chromosomes are bioriented in merotelic attachments.

mon in dividing cells, but are normally corrected early in mitosis $[11,12]$. The control of the mitotic spindle however is deregulated in most carcinomas, resulting in a self-amplifying loop of chromosomal instability. Recent advances underline the importance of spindle defects in the early stages of tumorigenesis, and generate a particular interest in the role of spindle-induced chromosome breakage as the initiator of chromosomal instability [13]. The aim of this paper is to discuss some of the signaling pathways that connect spindle defects, specifically merotelic attachments, to chromosome breakage and the regulation of cell cycle progression.

\section{Coping with merotelic attachments}

Uncorrected merotelic attachments lead to gains and losses of whole chromosomes, termed aneuploidy [11]. In addition, uncorrected merotelic attachments can exert sufficient force to distort individual kinetochores, which damages centromeric chromatin and causes chromosome rupture [13]. The alterations that result from uncorrected merotelic attachments (aneuploidy as well as losses and gains of chromosome arms) are among the most frequently observed genomic defects in cancer $[14,15]$. Since uncorrected merotelic attachments appear to be common in solid tumors, thery are thought to be a driving force behind the chromosomal instability (CIN) phenotype that accounts for approximately $85 \%$ of sporadic carcinomas $[16,17]$. The chromosome breakage that is associated with uncorrected merotelic attachments generates "reactive" chromosome arms that are able to fuse to intact chromosomes [17]. Such "reactive" arms could initiate the self-propagating chain of instability termed the breakagefusion-bridge cycle [18]. Whereas the DNA breakage products of uncorrected merotelic attachments, whole chromosome arms, are especially common in low-grade tumors, complex translocation patterns are characteristic of high-grade carcinomas $[19,20]$. In CIN tumors, uncorrected merotelic attachments might thus initiate genomic instability that is subsequently propagated by breakagefusion-bridge cycles [17]. Although uncorrected merotelic attachments are common in CIN tumors that show reduced spindle checkpoint control, some healthy cells also bear spindle defects. Genetic techniques using fluorescent probes that flank the centromere showed that a small proportion of normal lymphocytes undergo physical separation of the long and short arms of a single chromosome [21], indicating that some merotelic attachments lead inevitably to chromosome breakage. The uncorrected merotelic attachments responsible for the most important genomic alterations of CIN tumors thus occur occasionally in normal cells.

The prevalence of CIN in cancer and the evidence of uncorrected merotelic attachments in normal cells suggest that correct chromosome segregation is a fundamental problem in evolution, still not fully resolved. Some species, for example Muntiacus muntjak, Potorous tridactylis, and Wallabia bicolor [22-24], assemble their genome in a dozen or fewer chromosomes, with a concomitant reduction in centrosome number. Although low chromosome numbers reduce the number of kinetochores that require control in each cell division, individual kinetochores still form merotelic attachments in Potorous tridactylis cells [25]. An extremely low chromosome number nonetheless appears to prevent aneuploidy, thought to be one of the initiating events in tumorigenesis $[16,26]$. Conditions that readily induce aneuploidy in human and mouse cells only allow for loss or gain of the small sex chromosome Y2 in muntjac cells. Missegregation of the large chromosomes in muntjac is not tolerated due to gene dosage effects [27]. Most mammals must live with the occasional aneuploid cell, however, because they fully depend on spindle dynamics to detect and prevent chromosome missegregation [12,25]. 
Since the classical mitotic checkpoint fails to detect a proportion of merotelic attachments [8-10], a backup mechanism that detects the consequences of uncorrected merotelic attachments and prevents continuation of mitosis could provide a solution. In addition to aneuploidy, uncorrected merotelic attachments generate chromosome fragments, that is, the formation of doublestrand breaks (DSB). DSB could thus indicate a chromosome segregation problem to the cell. Intramitotic DNA damage indeed produces an anaphase delay signal; mammalian cells detect mitotic DNA breaks and respond by activating the spindle checkpoint [28-30]. The crosstalk between break repair and spindle control pathways might have a physiological function in the prevention of aneuploidy, since treatments that induce DNA damage cause aneuploidy in normal cells [31-33]. Although identification of damaged DNA seems a second-best solution, coupling DSB detection to anaphase delay serves the dual purpose of creating a time window for repair and reattaching spindle fibers to the kinetochore (Fig. 2). The situation is more complex in carcinomas that show a weakened response to anaphase delay signals, termed mitotic slippage [16,26]. Mitotic slippage and alterations in the primary detection of kinetochore attachment defects would increase the number of DSB, adding pressure to the detection and repair pathway. Although the break repair pathway might be activated by uncorrected merotelic attachments and the associated DNA damage, it would be ineffective in mitosis if a downstream anaphase delay signal is impaired or bypassed.

\section{How cells handle chromosome breaks in mitosis}

Although merotelic attachments are processed by various pathways, a small proportion escapes detection [21], leaving the daughter cells to deal with a fragmented chromosome. Relaxation of the spindle checkpoint exacerbates this problem [13], placing additional pressure on DNA break repair in CIN tumors. In mammalian cells, doublestrand breaks are repaired by two major processes, termed non-homologous end joining and homologous recombination [34]. The availability of repair pathways at the time and subcellular location of intra-mitotic DSB has important consequences; whereas non-homologous end joining repairs breaks by simple religation of two DNA ends, homologous recombination depends on a homologous DNA template. This means that non-homologous end joining can repair DSB throughout the cell cycle, but homologous recombination is virtually inactive in the G1 phase [35]. The DNA breaks caused by uncorrected merotelic attachments are physically the same as other DSB and their centromeric location does not in itself hinder efficient repair [36], but the cell cycle stage in which they are formed obliges the cell to correct DNA damage during or right after mitosis. In addition, some chromo-

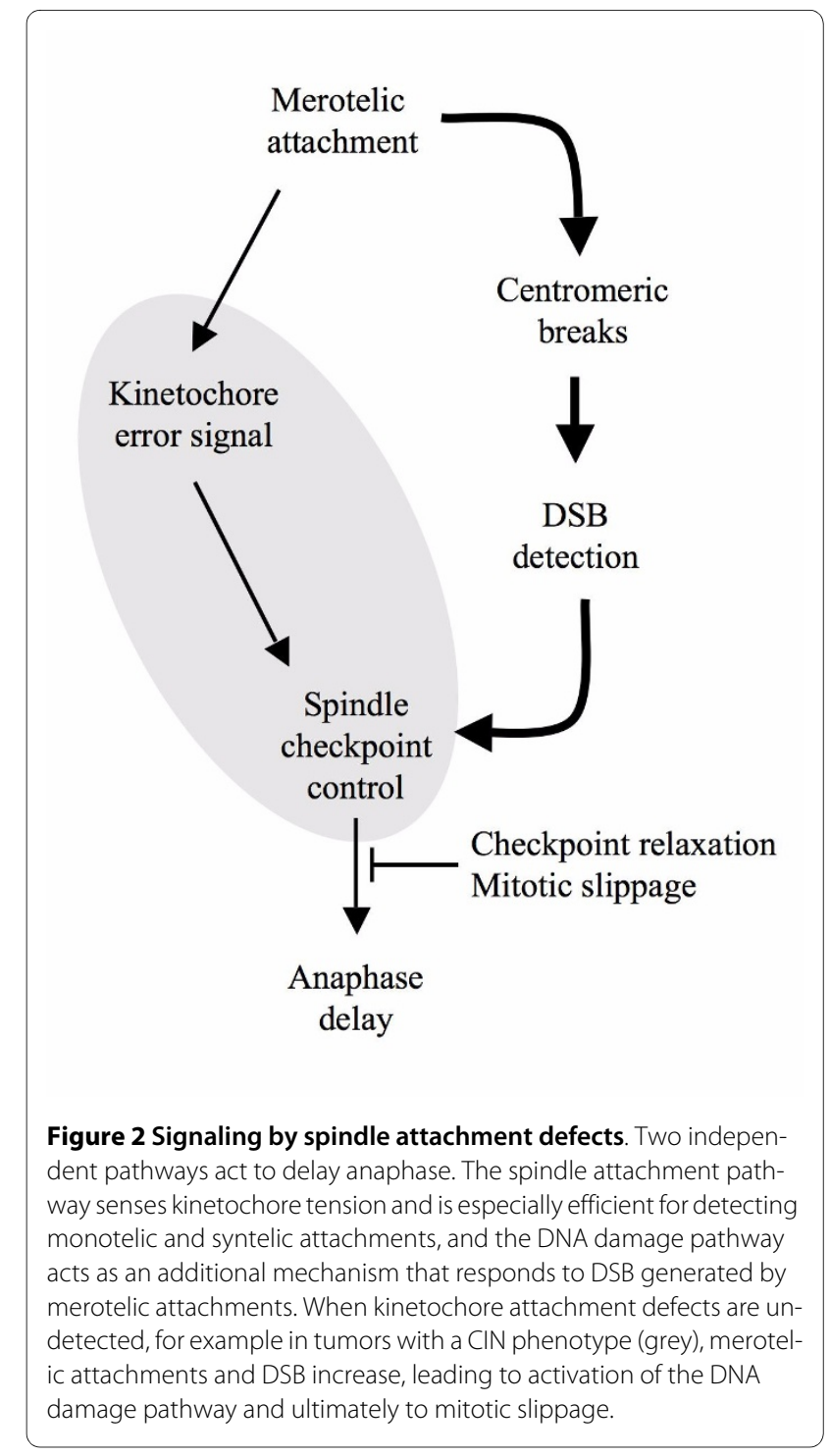

some fragments are sequestered in micronuclei [13], resulting in physical separation from the remainder of chromosomes and precluding homologous recombination.

Mice deficient in any of the DSB repair proteins are generally hypersensitive to induced DNA damage, although they are usually viable $[37,38]$. Whereas nonhomologous end joining or homologous recombination repair mutants have problems repairing induced DSB, the inactivation of a single repair pathway does not result in spontaneous DSB accumulation [13,39,40]. The absence of spontaneous DNA damage in mice lacking a single repair pathway implies that the endogenous DSB formation rate must be relatively low or at least is not life threatening. Notwithstanding the low frequency of spontaneous DSB, many tumors show increased repair system activity, in particular that of non-homologous end joining [41-43]. Non-homologous end joining activation in can- 
cer indicates that DSB are generated at an increased rate, possibly due to chromosome segregation errors and concomitant chromosome arm breakage.

\section{Non-homologous end joining is essential in a CIN background}

Non-homologous end joining appears to be especially important when spindle checkpoint control is relaxed, because the increase in uncorrected merotelic attachments could promote chromosome breakage. In nonhomologous end joining, Ku80 is essential for recruitment of repair complexes to DSB, whereas DNA-PKcs is the principal repair kinase [44]. Although residual nonhomologous end joining takes place in both Ku80- and DNA-PKcs-deficient cells, Ku80 mutation has a far greater impact on DSB repair kinetics than DNA-PKCs mutation [45-47]; DNA-PKcs disruption thus produces a milder phenotype than Ku80 inactivation. Targeted disruption of the death inducer obliterator (Dido) gene, which causes centrosome amplification and spindle checkpoint relaxation [48], results in a CIN phenotype that includes aneuploidy and chromosome breakage [13]. To determine whether non-homologous end joining is essential in a CIN background, we crossed Dido and $K u 80$ heterozygous mice, interbred the double heterozygotes and genotyped all offspring. Dido and DNA-PKcs heterozygous mice were interbred in the same way. In our crosses, heterozygous and wild-type pups were born at frequencies compatible with normal Mendelian inheritance; we found slightly fewer Ku80 and Dido mutant newborns (Table 1). In over 1000 pups tested, however, we identified no Dido Ku80 double mutants. When double heterozygous Dido DNA-PKcs mice were crossed, Dido mutants and Dido DNA-PKcs double mutants were born at frequencies below the expected ratio, but no marked effect of DNA-PKcs mutation was found (Table 2). Although the frequency of Ku80 mutants was reduced, some Dido Ku 80 double mutants would be expected; the absence of these double mutant mice thus indicates synthetic lethality, in accordance with the reported intramitotic DSB in the Dido mutant [13]. Mutation of Ku80 has a far greater impact on DSB repair kinetics than that of DNA-PKCs in models of induced DNA damage [49,50], and $D N A-P K c s$ also appears to be less important than $\mathrm{Ku} 80$ in the repair of DSB generated by uncorrected merotelic attachments.

Since Dido Ku80 double mutant embryos die in utero, we established the time of gestation at which death occurs. Double heterozygous Dido Ku80 mice were interbred and embryos analyzed by dark field microscopy at various times postcoitum. Mutant embryo development was not markedly different from that of heterozygous counterparts up to E8.5 (not shown). Growth delay in Dido Ku80 double mutant embryos was first apparent at E9.5, with underdeveloped head, heart and somites (Fig. 3). At E10.5, Dido and Ku80 single mutant embryos continued to develop normally, whereas most Dido Ku80 double mutant embryos had died and were being reabsorbed, and none survived beyond E12.5. Due to variation in survival, we were unable to define an exact time point of death. These data nonetheless show that Dido Ku80 double mutant embryos die in utero at mid-gestation, suggesting a role for non-homologous end joining in the repair of DNA damage generated by uncorrected merotelic attachments.

\section{Closing remarks}

Merotelic kinetochore attachments seem to be the Achilles' heel of mammalian cell division, as they can bring about potentially dangerous genomic instability but are

Table 1: Combined disruption of Dido and Ku80 is embryonic lethal.

\begin{tabular}{|c|c|c|c|}
\hline Ku80 & Dido & $N^{\circ}$ pups (expected) & $\mathrm{N}^{\circ}$ pups (observed) \\
\hline$+/+$ & $+/+$ & 78.75 & 147 \\
\hline$+/+$ & $+/$ neo & 157.50 & 278 \\
\hline$+/+$ & neo/neo & 78.75 & 49 \\
\hline$+/-$ & $+/+$ & 157.50 & 216 \\
\hline$+/-$ & $+/$ neo & 315.00 & 411 \\
\hline$+/-$ & neo/neo & 157.50 & 88 \\
\hline$-/-$ & $+/+$ & 78.75 & 24 \\
\hline$-/-$ & $+/$ neo & 157.50 & 47 \\
\hline$-/-$ & neo/neo & 78.75 & 0 \\
\hline Total & & 1260 & 1260 \\
\hline
\end{tabular}

Mice heterozygous for Dido and Ku80 were crossed and all viable pups were genotyped. Ku80- and Didoneo/neo pups were born at a lower frequency than heterozygous littermates. No double mutant mice were born in a population of $>1000$ animals. 
Table 2: Combined disruption of Dido and DNA-PKcs.

\begin{tabular}{cccc}
\hline DNA-PKcs & Dido & $\mathbf{N}^{\circ}$ pups (expected) & $\mathbf{N}^{\circ}$ pups (observed) \\
\hline$+/+$ & $+/+$ & 60.25 & 100 \\
$+/+$ & $+/$ neo & 120.50 & 162 \\
$+/+$ & neo/neo & 60.25 & 22 \\
$+/-$ & $+/+$ & 120.50 & 122 \\
$+/-$ & $+/$ neo & 241.00 & 273 \\
$+/-$ & neo/neo & 120.50 & 40 \\
$-/-$ & $+/+$ & 60.25 & 56 \\
$-/-$ & $+/$ neo & 120.50 & 169 \\
-/- & neo/neo & 60.25 & 20 \\
\hline Total & & & 964
\end{tabular}

Mice heterozygous for Dido and DNA-PKcs were crossed and all viable pups were genotyped. Whereas the numbers of wild-type,

heterozygous and DNA-PKcs mutant mice born are as expected, Dido and Dido DNA-PKcs mutant mouse numbers were below the expected frequency.

poorly recognized by the spindle checkpoint. Even in normal cells, a small proportion of cell divisions thus give rise to chromosome breakage [21]. In the case of intramitotic chromosome breakage, DSB repair systems could transmit a second signal in an attempt to delay mitosis progression [28-30]. The combination of signals involved in the detection of spindle errors has important consequences for cancer development, and gives rise to a working model of early tumorigenesis (Fig. 4).

Any minor alteration in spindle regulation could result in an increase in merotelic attachments that escape detection, giving rise to aneuploidy and chromosome breakage [13]. Breakage activates cellular DNA damage control, shown by increased DSB repair in many tumors [41-43]. The need for non-homologous end joining in a CIN background is emphasized by the synthetic lethality of Dido Ku 80 double mutants. DNA damage signaling provides feedback to the spindle checkpoint and delays mitosis progression, which prolongs the time window for repair and prevents aneuploidy. Repair by non-homologous end joining not only limits DNA damage and promotes cell survival, but also catalyzes the fusion of reactive chromosome ends. A chromosome fragment generated by spindle defects can thus form end-to-end fusions with normal chromosomes and initiate the breakage-fusion-bridge cycle [18]. Once the breakage-fusionbridge cycles commence, restoring spindle control no longer ensures stability, since dicentric chromosomes formed by end-to-end fusions can break, even though individual kinetochores are correctly attached $[17,18]$. A long term effect of DNA damage is cell immortalization; sustained breaks exert selective pressure to evade apoptosis and senescence [51]. Since DSB prevent the progres-

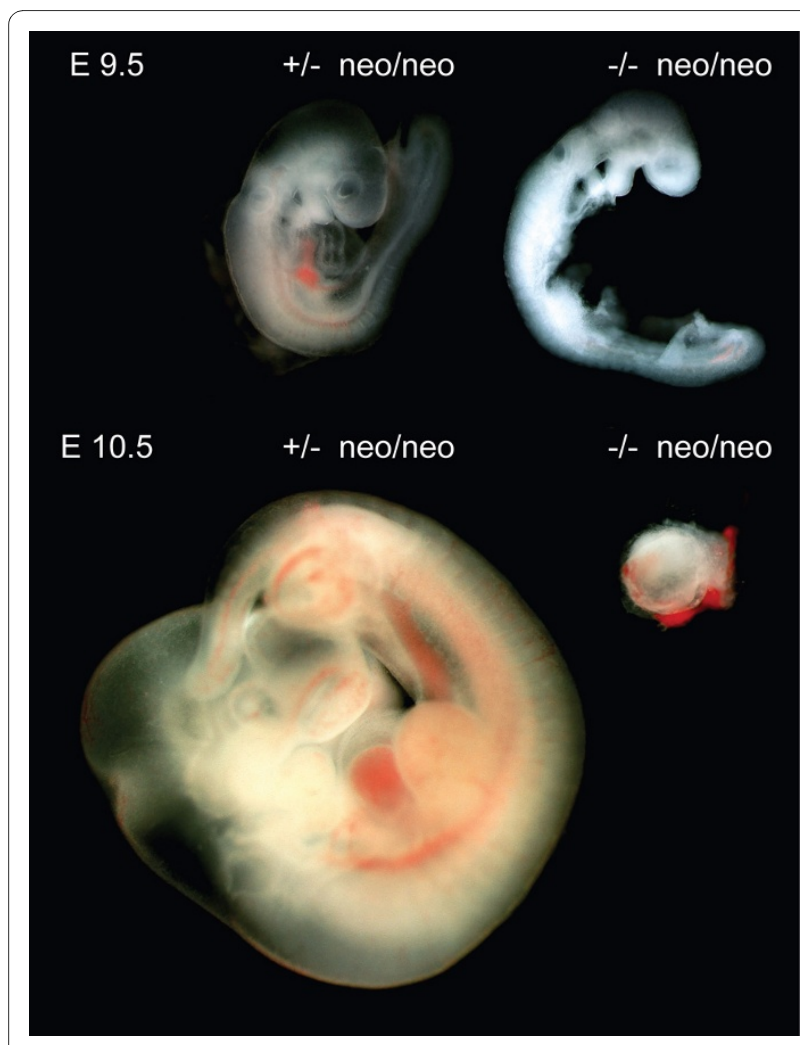

Figure 3 Combined disruption of Ku80 and Dido is lethal in midgestation. The figure shows embryos isolated at embryonic day E9.5 (top) and E10.5 (bottom). Ku80 heterozygous Dido mutant embryos are shown at left and Ku80 Dido double mutant embryos at right. At E9.5, double mutant embryos show growth delay in head, heart, and somites. At E10.5, most Ku80 Dido double mutant embryos are being resorbed. Magnification, 40-fold. All animal experiments were performed in compliance with EU and CNB animal committee directives. 


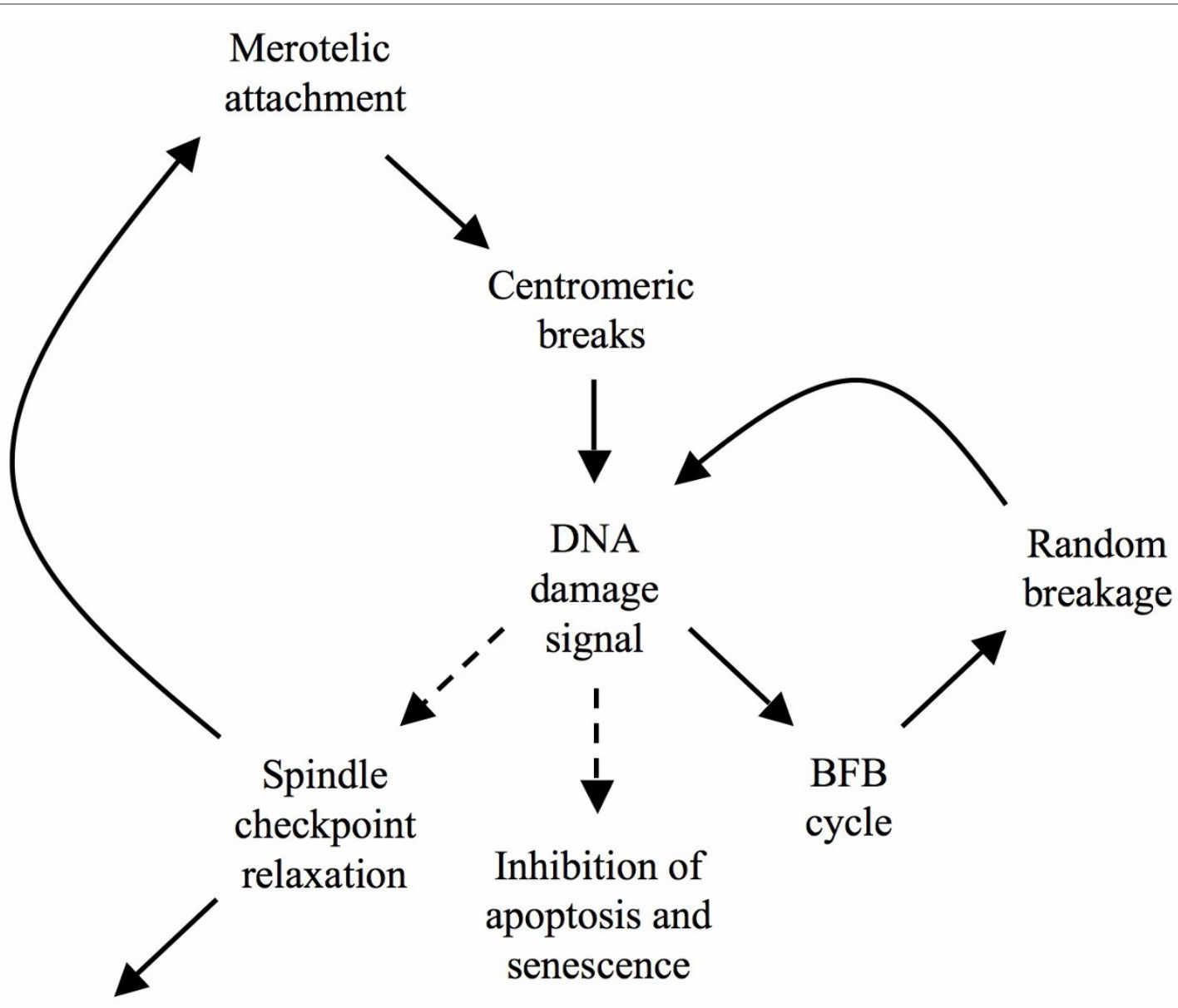

\section{Aneuploidy}

Figure 4 Model for amplification of chromosomal instability by DNA damage. Initial merotelic attachments activate DNA damage signaling and inhibit cell proliferation through anaphase delay and induction of apoptosis or senescence. To overcome the block, the downstream spindle checkpoint is suppressed in CIN tumors, increasing the frequency of spindle attachment errors. As a side effect of this continuous breakage, DNA repair mechanisms remain activated, leading ultimately to adaptation through suppression of apoptosis and senescence and through spindle checkpoint relaxation (dashed lines).

sion of mitosis, it is likely that sustained breaks also facilitate mitotic checkpoint relaxation. Continuous mitotic chromosome breakage could thus explain why, over time, CIN tumors become more malignant and refractory to treatment. In conclusion, nature's use of DSB repair systems as a backup for the detection of merotelic attachments might in fact promote chromosomal instability and act as a motor for carcinogenesis. CIN tumors show precisely the characteristics predicted by the above model: Most carcinomas show chromosomal instability and reduced control of the mitotic spindle, combined with enhanced DNA damage repair and reduced apoptotic potential. The challenge for cancer treatment will be to break this vicious circle without causing additional genomic instability.
Abbreviations

CIN: chromosomal instability; DSB: double strand DNA break.

Competing interests

The authors declare that they have no competing interests.

\section{Authors' contributions}

AAG performed experiments and analyzed data, CMA designed experiments, KvW wrote the paper. All authors read and approved the manuscript.

\section{Acknowledgements}

The authors thank Dr. Maria Blasco for Ku80 and DNA-PKCs mutant mice, and Catherine Mark for editorial assistance. The publication costs for this manuscript were financed by grant PS09/00572 (Fondo de Investigación en Salud) and the experimental work by grant S-BIO-0189-2006 (Comunidad Autonoma de Madrid). The Department of Immunology and Oncology was founded and is supported by the Spanish National Research Council (CSIC) and by Pfizer. 


\section{Author Details}

Department of Immunology and Oncology, Centro Nacional de Biotecnología/ CSIC, Darwin 3, UAM Campus Cantoblanco, 28049 Madrid, Spain

Received: 18 April 2010 Accepted: 17 May 2010

Published: 17 May 2010

\section{References}

1. Maiato H, Sunkel CE: Kinetochore-microtubule interactions during cell division. Chromosome Res 2004, 12:585-597.

2. Berlin RD, Oliver JM, Walter RJ: Surface functions during Mitosis I: phagocytosis, pinocytosis and mobility of surface-bound Con A. Cell 1978, 15:327-341.

3. Klein J, Grummt I: Cell cycle-dependent regulation of RNA polymerase I transcription: the nucleolar transcription factor UBF is inactive in mitosis and early G1. Proc Natl Acad Sci USA 1999, 96:6096-6101.

4. Gottesfeld JM, Forbes DJ: Mitotic repression of the transcriptional machinery. Trends Biochem Sci 1997, 22:197-202.

5. Simerly C, Balczon R, Brinkley BR, Schatten G: Microinjected centromere kinetochore antibodies interfere with chromosome movement in meiotic and mitotic mouse oocytes. J Cell Biol 1990, 111:1491-1504.

6. Wise DA, Bhattacharjee L: Antikinetochore antibodies interfere with prometaphase but not anaphase chromosome movement in living PtK2 cells. Cell Motil Cytoskeleton 1992, 23:157-167.

7. Maresca TJ, Salmon ED: Welcome to a new kind of tension: translating kinetochore mechanics into a wait-anaphase signal. J Cell Sci 2010, 123:825-835.

8. Cimini D, Fioravanti D, Salmon ED, Degrassi F: Merotelic kinetochore orientation versus chromosome mono-orientation in the origin of lagging chromosomes in human primary cells. J Cell Sci 2002, 115:507-515.

9. Lampson MA, Renduchitala K, Khodjakov A, Kapoor TM: Correcting improper chromosome-spindle attachments during cell division. Nat Cell Biol 2004, 6:232-237.

10. Cimini D, Wan $X$, Hirel CB, Salmon ED: Aurora kinase promotes turnover of kinetochore microtubules to reduce chromosome segregation errors. Curr Bio/ 2006, 16:1711-1718.

11. Cimini D, Howell B, Maddox P, Khodjakov A, Degrassi F, Salmon ED: Merotelic kinetochore orientation is a major mechanism of aneuploidy in mitotic mammalian tissue cells. J Cell Biol 2001, 153:517-527.

12. Cimini D, Moree B, Canman JC, Salmon ED: Merotelic kinetochore orientation occurs frequently during early mitosis in mammalian tissue cells and error correction is achieved by two different mechanisms. J Cell Sci 2003, 116:4213-4225.

13. Alonso Guerrero A, Cano Gamero M, Trachana V, Futterer A, Pacios-Bras C, Panadero Diaz-Concha N, Cigudosa JC, Martínez-A C, van Wely KH: Centromere-localized breaks indicate the generation of DNA damage by the mitotic spindle. Proc Nat/ Acad Sci USA 2010, 107:4159-4164.

14. Bignell GR, Greenman CD, Davies H, Butler AP, Edkins S, Andrews JM, Buck G, Chen L, Beare D, Latimer C, Widaa S, Hinton J, Fahey C, Fu B, Swamy S, Dalgliesh GL, Teh BT, Deloukas P, Yang F, Campbell PJ, Futreal PA, Stratton MR: Signatures of mutation and selection in the cancer genome. Nature 2010, 463:893-898.

15. Beroukhim R, Mermel CH, Porter D, Wei G, Raychaudhuri S, Donovan J, Barretina J, Boehm JS, Dobson J, Urashima M, Mc Henry K, Pinchback RM, Ligon AH, Cho YJ, Haery L, Greulich H, Reich M, Winckler W, Lawrence MS, Weir BA, Tanaka KE, Chiang DY, Bass AJ, Loo A, Hoffman C, Prensner J, Liefeld T, Gao Q, Yecies D, Signoretti S, et al.: The landscape of somatic copy-number alteration across human cancers. Nature 2010, 463:899-905.

16. Draviam VM, Xie S, Sorger PK: Chromosome segregation and genomic stability. Curr Opin Genet Dev 2004, 14:120-125.

17. Martínez-A C, van Wely KH: Are aneuploidy and chromosome breakage caused by a CINgle mechanism? Cell Cycle 2010, 9:12.

18. McClintock B: The Stability of Broken Ends of Chromosomes in Zea Mays. Genetics 1941, 26:234-282.

19. Schrock E, Blume C, Meffert MC, du Manoir S, Bersch W, Kiessling M, Lozanowa T, Thiel G, Witkowski R, Ried T, Cremer T: Recurrent gain of chromosome arm 7q in low-grade astrocytic tumors studied by comparative genomic hybridization. Genes Chromosomes Cancer 1996, 15:199-205.
20. Roylance R, Gorman P, Papior T, Wan YL, Ives M, Watson JE, Collins C, Wortham N, Langford C, Fiegler H, Carter N, Gillett C, Sasieni P, Pinder S, Hanby A, Tomlinson I: A comprehensive study of chromosome 16q in invasive ductal and lobular breast carcinoma using array CGH. Oncogene 2006, 25:6544-6553.

21. Rupa DS, Hasegawa L, Eastmond DA: Detection of chromosomal breakage in the 1cen-1q12 region of interphase human lymphocytes using multicolor fluorescence in situ hybridization with tandem DNA probes. Cancer Res 1995, 55:640-645.

22. Wurster DH, Benirschke K: Indian muntjac, Muntiacus muntjak: a deer with a low diploid chromosome number. Science 1970, 168:1364-1366.

23. Walen KH, Brown SW: Chromosomes in a marsupial (Potorous tridactylis) tissue culture. Nature 1962, 194:406.

24. Toder R, O'Neill RJ, Wienberg J, O'Brien PC, Voullaire L, Marshall-Graves JA: Comparative chromosome painting between two marsupials: origins of an XX/XY1Y2 sex chromosome system. Mamm Genome 1997, 8:418-422.

25. Cimini D, Cameron LA, Salmon ED: Anaphase spindle mechanics prevent mis-segregation of merotelically oriented chromosomes. Curr Biol 2004, 14:2149-2155.

26. Rajagopalan H, Lengauer C: Aneuploidy and cancer. Nature 2004, 432:338-341.

27. Vig BK, Henderson A: Aneuploidy in male Indian muntjac cells is limited to the Y2 chromosome. Mutagenesis 1998, 13:33-37.

28. Dotiwala F, Harrison JC, Jain S, Sugawara N, Haber JE: Mad2 Prolongs DNA Damage Checkpoint Arrest Caused by a Double-Strand Break via a Centromere-Dependent Mechanism. Curr Biol 2010, 20:328-332.

29. Fang Y, Liu T, Wang X, Yang YM, Deng H, Kunicki J, Traganos F, Darzynkiewicz Z, Lu L, Dai W: BubR1 is involved in regulation of DNA damage responses. Oncogene 2006, 25:3598-3605.

30. Mikhailov A, Cole RW, Rieder CL: DNA damage during mitosis in human cells delays the metaphase/anaphase transition via the spindleassembly checkpoint. Curr Biol 2002, 12:1797-1806.

31. Touil N, Elhajouji A, Thierens H, Kirsch-Volders M: Analysis of chromosome loss and chromosome segregation in cytokinesisblocked human lymphocytes: non-disjunction is the prevalent mistake in chromosome segregation produced by low dose exposure to ionizing radiation. Mutagenesis 2000, 15:1-7.

32. Kirsch-Volders M, Tallon I, Tanzarella C, Sgura A, Hermine T, Parry EM, Parry $J M$ : Mitotic non-disjunction as a mechanism for in vitro aneuploidy induction by X-rays in primary human cells. Mutagenesis 1996, 11:307-313.

33. Sgura A, Antoccia A, Cherubini R, Tanzarella C: Chromosome nondisjunction and loss induced by protons and $\mathrm{X}$ rays in primary human fibroblasts: role of centromeres in aneuploidy. Radiat Res 2001, 156:225-231.

34. Bernstein C, Bernstein H, Payne CM, Garewal H: DNA repair/proapoptotic dual-role proteins in five major DNA repair pathways: failsafe protection against carcinogenesis. Mutat Res 2002, 511:145-178.

35. Rothkamm K, Kruger I, Thompson LH, Lobrich M: Pathways of DNA double-strand break repair during the mammalian cell cycle. Mol Cell Biol 2003, 23:5706-5715.

36. Rief $\mathrm{N}$, Lobrich $\mathrm{M}$ : Efficient rejoining of radiation-induced DNA doublestrand breaks in centromeric DNA of human cells. J Biol Chem 2002, 277:20572-20582.

37. Taccioli GE, Amatucci AG, Beamish HJ, Gell D, Xiang XH, Torres Arzayus MI, Priestley A, Jackson SP, Marshak Rothstein A, Jeggo PA, Herrera VL: Targeted disruption of the catalytic subunit of the DNA-PK gene in mice confers severe combined immunodeficiency and radiosensitivity. Immunity 1998, 9:355-366.

38. Barlow C, Hirotsune S, Paylor R, Liyanage M, Eckhaus M, Collins F, Shiloh Y, Crawley JN, Ried T, Tagle D, Wynshaw-Boris A: Atm-deficient mice: a paradigm of ataxia telangiectasia. Cell 1996, 86:159-171.

39. Stiff T, O'Driscoll M, Rief N, Iwabuchi K, Lobrich M, Jeggo PA: ATM and DNA-PK function redundantly to phosphorylate $\mathrm{H} 2 \mathrm{AX}$ after exposure to ionizing radiation. Cancer Res 2004, 64:2390-2396.

40. Suzuki K, Okada H, Yamauchi M, Oka Y, Kodama S, Watanabe M: Qualitative and quantitative analysis of phosphorylated ATM foci induced by low-dose ionizing radiation. Radiat Res 2006, 165:499-504.

41. Gaymes TJ, Mufti GJ, Rassool FV: Myeloid leukemias have increased activity of the nonhomologous end-joining pathway and concomitant 
DNA misrepair that is dependent on the Ku70/86 heterodimer. Cancer Res 2002, 62:2791-2797.

42. Hosoi Y, Watanabe T, Nakagawa K, Matsumoto Y, Enomoto A, Morita A, Nagawa H, Suzuki N: Up-regulation of DNA-dependent protein kinase activity and Sp1 in colorectal cancer. Int J Oncol 2004, 25:461-468.

43. Pucci S, Mazzarelli P, Rabitti C, Giai M, Gallucci M, Flammia G, Alcini A Altomare V, Fazio VM: Tumor specific modulation of KU70/80 DNA binding activity in breast and bladder human tumor biopsies. Oncogene 2001, 20:739-747.

44. Collis SJ, DeWeese TL, Jeggo PA, Parker AR: The life and death of DNA-PK. Oncogene 2005, 24:949-961.

45. Secretan MB, Scuric Z, Oshima J, Bishop AJ, Howlett NG, Yau D, Schiestl RH: Effect of Ku86 and DNA-PKcs deficiency on non-homologous endjoining and homologous recombination using a transient transfection assay. Mutat Res 2004, 554:351-364.

46. Iliakis G, Wang H, Perrault AR, Boecker W, Rosidi B, Windhofer F, Wu W, Guan J, Terzoudi G, Pantelias G: Mechanisms of DNA double strand break repair and chromosome aberration formation. Cytogenet Genome Res 2004, 104:14-20.

47. Tzung TY, Runger TM: Reduced joining of DNA double strand breaks with an abnormal mutation spectrum in rodent mutants of DNA-PKcs and Ku80. Int J Radiat Biol 1998, 73:469-474.

48. Trachana V, van Wely KH, Guerrero AA, Futterer A, Martínez-A C: Dido disruption leads to centrosome amplification and mitotic checkpoint defects compromising chromosome stability. Proc Natl Acad Sci USA 2007, 104:2691-2696.

49. Chen S, Inamdar KV, Pfeiffer P, Feldmann E, Hannah MF, Yu Y, Lee JW, Zhou T, Lees-Miller SP, Povirk LF: Accurate in vitro end joining of a DNA double strand break with partially cohesive 3'-overhangs and 3'phosphoglycolate termini: effect of Ku on repair fidelity. J Biol Chem 2001, 276:24323-24330

50. Cheong N, Perrault AR, Wang H, Wachsberger P, Mammen P, Jackson I, Iliakis G: DNA-PK-independent rejoining of DNA double-strand breaks in human cell extracts in vitro. Int J Radiat Biol 1999, 75:67-81.

51. Bartek J, Lukas J: DNA damage checkpoints: from initiation to recovery or adaptation. Curr Opin Cell Biol 2007, 19:238-245.

doi: $10.1186 / 1747-1028-5-13$

Cite this article as: Guerrero et al., Merotelic attachments and non-homologous end joining are the basis of chromosomal instability Cell Division 2010, 5:13

Submit your next manuscript to BioMed Central and take full advantage of:

- Convenient online submission

- Thorough peer review

- No space constraints or color figure charges

- Immediate publication on acceptance

- Inclusion in PubMed, CAS, Scopus and Google Scholar

- Research which is freely available for redistribution 